\title{
TO DETERMINE THE FREQUENCY OF OPERATIONS IN ACUTE APPENDICITIS AFTER ANTIBIOTIC THERAPY.
}

1. FCPS

Assistant Professor

Department of Surgery

Aziz Fatima Medical and

Dental College, Faisalabad

2. FCPS

Senior Registrar

Department of Surgery

DHQ Hospital Faisalabad.

3. FCPS

Senior Registrar Department of Surgery

DHQ Hospital Faisalabad.

Correspondence Address: Dr. Sarwat Bibi

House No 89-C, PMC Colony,

Daewoo Road, Faislabad.

amarbail82@yahoo.com

Article received on:

$21 / 01 / 2019$

Accepted for publication:

20/05/2019

Received after proof reading:

$31 / 07 / 2019$

\begin{abstract}
Sarwat Bibi', Junaid Misbah'², Khurram Saqib ${ }^{3}$
ABSTRACT... A descriptive, cross sectional study conducted to evaluate the results of conservative management of acute appendicitis with antibiotic therapy. Study Design: Descriptive, cross sectional study. Setting: Surgical Unit of Aziz Fatima Trust Hospital. Period: $1^{\text {st }}$ Jan 2017 to $31^{\text {st }}$ December 2018. Materials and Methods: The objective of this study is to determine the frequency of operations in acute appendicitis being treated by antibiotic therapy. A total of 140 patients were included in this study. Study patients having a modified Alvarado score of 7-9 received intravenous antibiotics (ciprofloxacin $400 \mathrm{mg}$ twice and metronidazole $500 \mathrm{mg}$ thrice) for at least 24 hours. Patients' whose status were improved as monitored by an improved modified Alvarado score and a decreased serial $\mathrm{C}$ reactive Protein measurement on the following morning, were discharged to continue with oral antibiotics. In patients whose clinical condition had not improved, intravenous treatment was prolonged for 48 hours and in case of deterioration in clinical condition, they were subjected to appendicectomy. Results: Mean age of the patients was $25.41 \pm 7.28$ years. Out of 140 patients, $51(36.4 \%)$ were male while remaining 89 patients $(63.6 \%)$ were female. Regarding Alvarado score, 53 patients $(37.9 \%)$ had 7 score, 60 patients (42.9\%) had 8 score and 27 patients (19.6\%) had 9 score. Mean Alvarado score was observed $7.81 \pm 0.73$. Operation was needed in 13 patients $(9.3 \%)$. Conclusion: In conclusion, acute appendicitis can be treated successfully with antibiotics. However, there is a risk of recurrence in cases of acute appendicitis, and this risk should be compared with the risk of complications after appendectomy.
\end{abstract}

Key words: $\quad$ Acute Appendicitis, Alvarado Score, Antibiotics, Perforation, Operations.

Article Citation: Bibi S, Misbah J, Saqib K. To determine the frequency of operations in acute appendicitis after antibiotic therapy. Professional Med J 2019; 26(8):12331237. DOI: 10.29309/TPMJ/2019.26.08.3167

\section{INTRODUCTION}

Acute appendicitis is one of the common presentations in surgical emergencies. The risk that a patient will develop acute appendicitis during lifetime is $8.6 \%$ among male population and $6.7 \%$ among female population. On the other side, the risk that a patient will undergo appendicectomy is opposite to that of acute appendicitis, with $12 \%$ for male individuals and $23 \%$ for female individuals. ${ }^{1}$ Acute appendicitis is a disease that increases progressively and ultimately leads to perforation. This was considered by surgeons for more than 100 years. In the last few decades the theories about this concept has gained attention, especially in adults. However, the most common urgent/emergent surgical procedure for acute appendicitis is appendicectomy. At present, there are increased number of evidences that show that the clinical practice for the management of acute appendicitis is changing towards the conservative treatment whether it is noncomplicated or complicated. ${ }^{2}$ The main treatment option for acute appendicitis is surgery and that is appendicectomy for previous many decades. Many patients have been treated conservatively with medicines previously but conservative treatment as well as post appendicectomy patients were associated with high morbidity and mortality. It was thought previously that appendicectomy should be done as early as possible in patients with acute appendicitis so that complications can be avoided like perforation but many studies have evaluated that late complications after surgical treatment for appendicitis are quite significant: small bowel obstruction that needs surgery occurs in $1.3 \%$ after 30 years, and thirty 
day mortality is $0.24 \%$ with increased standard mortality ratio. The operation rate was $10 \%$ in patients who were managed conservatively with antibiotics. ${ }^{3}$ Negative appendicectomy rate is quite high that ranges from $2-41 \%$ and several authors believe that higher negative appendicectomy rates are acceptable to avoid complications like perforation. ${ }^{4}$ The surgical belief that emergent appendicectomy is standard treatment, has shown a paradigm shift to a non-operative approach. ${ }^{5}$ That is why, there is lot of discussion about the different treatment options of acute appendicitis and now it is believed that major number of patients who have uncomplicated acute appendicitis can be treated with antibiotics instead of surgery. ${ }^{6}$ The most recent meta-analysis published in 2010 showed that the patients who received conservative treatment have low overall complications rate as compared to those who underwent immediate appendicectomy. There was no difference in the duration of stay after first admission, total duration of stay in hospital and dosage of intravenous (IV) antibiotics therapy between two groups. ${ }^{7}$ and it has been proposed conservative treatment of acute appendicitis is quite safe as, as it leads to decreased overall complications later on, and lower risk of re operations for complications. Some studies have shown that in children even complications of appendicitis like perforation can be treated with antibiotics alone. ${ }^{8}$

\section{PATIENTS AND METHODS}

The descriptive, cross sectional study was done in surgical unit of Aziz Fatima trust hospital from 1st Jan $2017-31^{\text {st }}$ December 2018. A total of 140 consecutive patients were part of the study who had acute appendicitis with Alverado score of 7-9. The patients having complication of acute appendicitis like perforation, abscess or mass were excluded from study. Study patients having a modified Alvarado score of 7-9 were given intravenous antibiotics (ciprofloxacin 400mg twice and metronidazole $500 \mathrm{mg}$ thrice) for first 24 hours. During this time, patients were kept nill by mouth and were given intravenous fluids. Patients who were improved clinically as monitored by an improved modified Alvarado score and a decreased serial $C$ reactive Protein measurement on the next morning, were sent home and advised to take oral antibiotics (ciprofloxacin $500 \mathrm{mg}$ two times a day and metronidazole 400 $\mathrm{mg}$ three times a day for 10 days. The patients who were not improved clinically, intravenous antibiotics was given for 48 hours and in case of deterioration in clinical condition, would be subjected to appendicectomy. The patients were followed for 6 weeks by using their contact numbers. The data obtained was entered in SPSS version 18. Organized and tabulated according to variables. Descriptive statistics was calculated for all variables. Mean and standard deviation was calculated for all quantitative variables like age and Alvarado score. Frequency and percentages were calculated for all qualitative variables like gender and reoperation within 6 weeks.

\section{RESULTS}

140 patients were recruited in current study between January 2017-December 2018. Majority of the patients were between 20-30 years of age while least patients were between 41-60 years old. Mean age of the patients was $25.41 \pm 7.28$ years.

Distribution of cases by age (Table-I)

\begin{tabular}{|l|c|c|}
\hline \multicolumn{1}{|c|}{ Age (Year) } & Number & Percentage \\
\hline$<20$ & 31 & 22.2 \\
\hline $20-30$ & 77 & 55.0 \\
\hline $31-40$ & 28 & 20.0 \\
\hline $41-60$ & 04 & 02.8 \\
\hline Total & 140 & 100.0 \\
\hline Mean \pm SD & \multicolumn{2}{|c|}{$25.41 \pm 7.28$} \\
\hline
\end{tabular}

Out of 140 patients, 51 (36.4\%) were male while remaining 89 patients $(63.6 \%)$ were female (TableII).

\begin{tabular}{|l|c|c|}
\hline \multicolumn{1}{|c|}{ Gender } & Number & Percentage \\
\hline Male & 51 & 36.4 \\
\hline Female & 89 & 63.6 \\
\hline Total & 140 & 100.0 \\
\hline
\end{tabular}

Regarding Alvarado score, 53 patients (37.9\%) had 7 score, 60 patients (42.9\%) had 8 score and 27 patients (19.6\%) had 9 score. Mean Alvarado score was observed $7.81 \pm 0.73$. Table-III 


\begin{tabular}{|l|c|c|}
\hline \multicolumn{1}{|c|}{ Score } & Number & Percentage \\
\hline 7 & 53 & 37.9 \\
\hline 8 & 60 & 42.9 \\
\hline 9 & 27 & 19.3 \\
\hline Total & 140 & 100.0 \\
\hline Mean \pm SD & \multicolumn{2}{|c|}{$7.81 \pm 0.73$} \\
\hline
\end{tabular}

Reoperation was needed in 13 patients (9.3\%). Table-IV

\begin{tabular}{|l|c|c|}
\hline Reoperation & Number & Percentage \\
\hline Yes & 13 & 09.3 \\
\hline No & 127 & 90.7 \\
\hline Total & 140 & 100.0 \\
\hline
\end{tabular}

\section{DISCUSSION}

Previous studies comparing antibiotics with surgery have been published during recent years, but there are no unanimous conclusions in these studies. Some authors said that antibiotics can be used safely as complications rate is low, but some reports emphasized that the gold standard treatment for acute appendicitis is still appendicectomy. ${ }^{9}$ In another study, Abbas M et al. concluded that the efficacy of antibiotic treatment is $90.625 \%$ where as in case of appendicectomy it was $88.46 \%(p=0.759)$ after one month of treatment. After the treatment of one year, there was no statistically significant difference $(p=0.055)$ between effect of antibiotics $(71.87 \%)$ and appendicectomy (87.14\%). The efficacy of antibiotic treatment is same as appendicectomy in acute appendicitis at 1 month and 1 year post treatment. ${ }^{10}$

Others said that antibiotic treatment results in less number of complications than surgery and could be considered as an alternative treatment in a majority of patients when such patients are ready to accept either a risk of treatment failure after initial conservative management or risk of recurrence afterwards. ${ }^{11,12}$ According to some previous studies, the antibiotic therapy is not very effective treatment option, as for example in the study by Vons et al amoxicillin-clavulanic acid was used but the failure rate after combination of these two drugs is quite high. Furthermore, the use of this combination is associated with not only treatment failure but also high rate of recurrence of acute appendicitis. So this antibiotic treatment is not recommended for conservative treatment of acute appendicitis. ${ }^{13}$ The commonest pathogen responsible for acute appendicitis is Escherichia coli, others include Enterococcus and other Streptococcus species. Pseudomonas, Klebsiella, and Bacteroides species are usually not involved in acute appendicitis. That is why, when patients with acute appendicitis are managed conservatively, those antibiotics should be given that are effective against both aerobic and anaerobic bacteria. ${ }^{14}$ In our study, appendicectomy was required in only $9.3 \%$ of patients. Our findings are comparable with the following studies. Vons et al concluded that a recurrence of acute appendicitis was seen in $26 \%$ of patients who were treated with antibiotic. However, $68 \%$ of the patients were treated successfully with antibiotics in their study and these patients did not require appendicectomy supporting our study results that the major no. of patients $(90.7 \%)$ with acute appendicitis respond to antibiotics. So no. of negative appendicectomies can be significantly reduced and also the morbidity and mortality associated with surgical exploration of acute appendicitis. It also results in low cast of treatment and surgical resources can be used for many other emergency surgical procedures.

A study published in June 2015 in The Journal of the American Medical Association (JAMA) reported that antibiotic treatment has high failure rate. In patients who presented with uncomplicated appendicitis (as proved by a CT scan), 27 percent needed surgical exploration within one year of presentation. Still, there is significant number of patients who were managed successfully with antibiotic treatment and they did not require appendicectomy during the one-year follow-up period. ${ }^{15}$ Prior trials, that randomized the patients with appendicitis who received antibiotics treatment and who underwent appendecectomy, were followed for cure of disease. It was observed how many patients needed surgery who were being treated with antibiotics. Previous studies were done in which more than 800 patients were treated with 
antibiotics and they concluded that the antibiotic treatment is safe and it is not associated with complications and in more than $75 \%$ of patients, appendicectomy can be avoided. ${ }^{16}$ Our results are also close to the study of Malik and Bari where operation rate was $10 \%$ in group who was conservatively managed with antibiotics. ${ }^{2}$ The authors also compared complications between the patients who were treated with antibiotic and those who underwent appendicectomy. After 5 years, the complication rate was significantly higher in patients who underwent appendicectomy (24.4\%) compared to those who received antibiotics (6.5\%). Complication rate was almost similar in patients who underwent appendicectomy including those who initially received antibiotic treatment which showed that delay in surgery did not increase the risk of complications. ${ }^{17}$ In another study, 10 patients out of $96(10.41 \%)$ had worsening of symptoms (pain on visual analogue scale) and were confirmed with white blood count \& Ultrasound reports and they underwent appendectomy during initial hospital stay. While within 9 months of follow up, 11 (11.45\%) patients were readmitted in hospital and operated after confirming the diagnosis with help of clinical re-examination and re- investigations. Total of 21 (22\%) patients were subjected to appendectomy. ${ }^{18}$

\section{CONCLUSION}

In conclusion, antibiotic therapy can cure acute appendicitis successfully. However, there is a chance of recurrent appendicitis, and this risk should be compared with the risk of complications associated with appendicectomy. It is also cost effective.

\section{Copyright@ 20 May, 2019.}

\section{REFERENCES}

1. Snyder MJ, Guthrie M, Cagle S. Acute appendicitis: Efficient diagnosis and management. Am Fam Physician. 2018; 98:25-33.

2. Coccolini F1, Fugazzola P, Sartelli M et al. Conservative treatment of acute appendicitis. $2018 \mathrm{Dec} 17$; 89:11934.

3. Malik AA, Bari S. Conservative management of acute appendicitis. J Gastrointest Surg 2009; 13: 966-70.
4. Khanzada T, Samad A, Sushel C. Negative Appendectomy Rate: Can It Be Reduced? J Liaquat Univ Med Health Sci January-April 2009; 08:19-22.

5. Rollins KE, Varadhan KK, Neal KR, Lobo DN. Antibiotics versus appendicectomy for the treatment of uncomplicated acute appendicitis: an updated meta-analysis of randomized controlled trials. World J Surg. 2016; 40:2305-18.

6. Sallinen V, Tikkinen KA. Antibiotics or Appendectomy for acute non-perforated appendicitis--how to interpret the evidence? Scand J Surg 2016; 105:3-4.

7. Simillis C, Symeonides P, Shorthouse AJ, Tekkis PP. A meta-analysis comparing conservative treatment versus acute appendectomy for complicated appendicitis (abscess or phlegmon). Surgery. 2010; 147:818-29.

8. Levin T, Whyte C, Borzykowski R, Han B, Blitman N, Harris $B$. Nonoperative management of perforated appendicitis in children: Can CT predict outcome? Pediatr Radiol 2007; 37:251-5.

9. Fitzmaurice GJ, McWilliams $B$, Hurreiz $H$, Epanomeritakis, E. Antibiotics versus appendectomy in the management of acute appendicitis: A review of the current evidence. Can J Surg 2011; 54:6610.

10. Gulshan Ali Memon, Khawar Saeed Jamali, Syed Kashif Ali Shah, Habib-ur Rehman, Shahnawaz Leghari, Shahida Baloch. Outcomes of antibiotics as primary therapy in uncomplicated acute appendicitis at PUMHS Nawabshah. J Dow Uni Health Sci Jan - Apr 2017; 11:6-10.

11. Liu K, Fogg L. Use of antibiotics alone for treatment of uncomplicated acute appendicitis: A systematic review and meta-analysis. Surgery 2011; 150:673-83.

12. Mason R, Moazzez A, Sohn H, Katkhouda N. MetaAnalysis of randomized trials comparing antibiotic therapy with appendectomy for acute uncomplicated (No Abscess or Phlegmon) appendicitis. Surg Inf 2012; 13:74-84.

13. Mazuski JE, Solomkin JS. Intra-abdominal infections. Surg Clin North Am 2009; 89:421-37.

14. Wilms IM, de Hoog DE, de Visser DC, Janzing HM. Appendectomy versus antibiotic treatment for acute appendicitis. Cochrane Database Syst Rev 2011;11.

15. Paulina Salminen, MD, PhD1,2; Hannu Paajanen, MD, PhD3,4; Tero Rautio, MD, PhD5; et al. Antibiotic therapy vs appendectomy for treatment of uncomplicated acute appendicitis. The APPAC Randomized Clinical Trial. JAMA. 2015; 313:2340-48. 
16. Salminen P, Paajanen H, Rautio T, et al. Antibiotic therapy vs appendectomy for treatment of uncomplicated acute appendicitis: The APPAC randomized clinical trial. JAMA 2015; 313:2340-8.

17. Salminen $P$, Tuominen $R$, Paajanen $H$, et al. Five-year follow-up of antibiotic therapy for uncomplicated acute appendicitis in the APPAC randomized clinical trial. JAMA. 2018; 320:1259-65.
18. Gulshan Ali Memon, Khawar Saeed Jamali, Syed Kashif Ali Shah, Habib-ur Rehman, Shahnawaz Leghari, Shahida Baloch. Outcomes of Antibiotics as Primary Therapy in Uncomplicated Acute Appendicitis at PUMHS Nawabshah. J Dow Uni Health Sci Jan - sApr 2017; 11:6-10.

\section{AUTHORSHIP AND CONTRIBUTION DECLARATION}

\begin{tabular}{|c|c|c|c|}
\hline Sr. \# & Author-s Full Name & Contribution to the paper & Author $=\mathbf{s}$ Signature \\
\hline 1 & Sarwat Bibi & $\begin{array}{l}\text { Article writing \& Final } \\
\text { compilation. }\end{array}$ & \\
\hline 2 & Junaid Misbah & $\begin{array}{l}\text { Data collection, Helped in } \\
\text { Disscusion writing. }\end{array}$ & \\
\hline 3 & Khurram Saqib & $\begin{array}{l}\text { Resutls, Conclusion, } \\
\text { References. }\end{array}$ & \\
\hline
\end{tabular}

